\title{
Uma Nova espécie de Ocotea (Lauraceae) para o estado do Espírito Santo, Brasil
}

Alexandre Quinet ${ }^{1}$

\section{Resumo}

(Uma nova espécies de Ocotea (Lauraceae) para o estado do Espírito Santo, Brasil) É descrita e ilustrada uma nova espécie de Ocotea para o estado do Espírito Santo - O. pluridomatiata A. Quinet.

Palavras-chave: Ocotea pluridomatiata, nova espécie, floresta atlântica.

\section{Abstract}

(A new species of Ocotea (Lauraceae) from Espírito Santo State, Brasil) A new species of Ocotea from Espírito Santo is described and ilustrated - O. pluridomatiata A. Quinet.

Key words: Ocotea pluridomatiata, new species, Atlantic forest.

\section{INTRODUÇÃO}

As Lauraceae têm distribuição pantropical sendo bem representadas na América, Ásia tropical, Austrália e Madagascar e pouco expressivas no sul da África, possuindo cerca de 2.500 espécies subordinadas a 50 gêneros (Rohwer 1993). No Brasil ocorrem 22 gêneros que habitam em sua maior parte as florestas pluviais e também as restingas e os cerrados (Quinet 2002). Economicamente, o grupo se destaca pelo uso madeireiro e de óleos aromáticos muitas vezes empregados na confecção de perfumes e remédios.

Ocotea é constituído por cerca de 350 espécies distribuídas na América tropical e subtropical, desde o México até a Argentina. Com poucas espécies na África e em Madagascar e ausentes na Ásia (Rohwer 1993). O gênero caracteriza-se por apresentar flores monoclinas ou diclinas, com 6 tépalas, as flores estaminadas androceu com 9 estames férteis, anteras quadrilocelares, locelos dispostos em pares superpostos; estames das séries I e II com 3 estames cada, anteras introrsas; estames da série III com 3 estames, par de glândulas na base dos filetes, reduzidos, anteras extrorsas; série IV estaminodial ausente ou quando presente com 3 estaminódios, em geral reduzidos, filiformes, ou raramente estaminódios bem desenvolvidos, cordados ou sagitados; pistilóide presente ou ausente. Flores pistiladas com estaminódios reduzidos, de morfologia semelhante aos estames das flores estaminadas, com vestígio de locelos dispostos em dois pares superpostos. Fruto bacáceo, sobre ou parcialmente envolvido pela cúpula, em geral com margem simples e tépalas decíduas.

A revisão taxonômica das espécies do gênero Ocotea para a Região Sudeste do Brasil em andamento, vem proporcionando a análise das coleções depositadas nos principais herbários brasileiros. O estudo da coleção depositada no herbário Mello Leitão (MBML), e da Companhia Vale do Rio Doce (CVRD), em conjunto com um intensivo trabalho de campo, e da análise de literatura e dos espécimes tipo possibilitou identificar uma nova espécie para a ciência, sendo esta até o momento endêmica do estado do Espírito Santo e descrita no presente estudo.

Ocotea pluridomatiata A. Quinet, sp. nov. Tipo: BRASIL. ESPÍRITO SANTO: Santa Teresa, Reserva Biológica Santa Lúcia, parte baixa da cachoeira do rio Timbuí, 5.V.1999, fl., masc., W. P. Lopes, E. Bausen \& W. Pizziolo 621 (Holótipo RB; Isótipos - MBML, UEC).

Fig. 1

Ocoteae laxae (Nees) Mez forma laminae folii et antheris proxima, sed lamina folii domatiis copiosis in axillis nervorum secundariorum et tertiorum, filamentis

Artigo recebido em 08/2007. Aceito para publicação em 04/2008.

${ }^{1}$ Instituto de Pesquisas Jardim Botânico do Rio de Janeiro, Rua Pacheco Leão 915, 22460-030, Jardim Botânico, Rio de Janeiro, RJ, Brasil. aquinet@jbrj.gov.br 
staminum serierum I et II 0.6-0.8 mm longis et tepalis deciduis differt (domatia tantum in axillis nervorum secundariorum, filamenta staminum 0.2-0.3 mm longa et fructibus tepalis persistentibus in $\mathrm{O}$. laxa).

Árvores 8 a $25 \mathrm{~m}$ alt., dióicas, ramos cilíndricos, glabrescentes; gemas apicais áureo - tomentosas. Folhas alternas em todo o ramo, pecíolos delgados, canaliculados, esparsamente áureo- pubérulos; lâmina cartácea, elíptica, 4,6-7,6 × 1,9-2,8 cm, base cuneada, margem espessa, ápice acuminado a caudado; face adaxial glabra, face abaxial áureo-pubérula; nervura principal impressa na face adaxial, proeminente na face abaxial; padrão de nervação camptódromo - broquidódromo, nervuras secundárias conspícuas em ambas as faces, delgadas, 5-7 pares, alternos a subopostos, ângulo de divergência $50^{\circ}$ e $60^{\circ}$, reticulado laxo, grande número de domácias em tufos de pêlos nas axilas de nervuras secundárias e de terciárias. Inflorescência botrióide 2-3 cm compr., axilares. Flores diclinas, alvas, hipanto áureo - tomentoso. Flores masculinas com tépalas ovadas, 1,21,4 mm de compr., ápice obtuso, face externa e interna esparsamente áureo - tomentosa, papilosa. Estames das séries I e II com filetes $0,6-0,8 \mathrm{~mm}$ compr., anteras quadrilocelares, ovais a orbiculares, $8-10 \mathrm{~mm}$ compr., papilosas, introrsas; estames da série III com filetes 810 mm compr., par de glândula acima da base, anteras retangulares, 5-7 $\mathrm{mm}$ compr., papilosas, lateralmente extrorsas; série IV estaminodial ausente. Pistilóide ausente. Flores femininas com estaminódios de morfologia semelhante às das flores masculinas; ovário elipsóide, glabro, estilete curto, estigma indiviso. Fruto globoso, 0,7-1,2 cm compr., sobre cúpula taciforme, 0,5-0,7 cm compr., tépalas decíduas. Parátipo: BRASIL. ESPÍRITO SANTO: Santa Teresa, Estação Biológica Santa Lúcia, 28. IV. 1995, fr., L. D. Thomaz 1168 (MBML, RB, UEC); trilha do sagüi, 22.IX.1999, fr., V. Demuner et al. 11 (MBML, RB, UEC); Santo Antônio, terreno do Boza, 31.III.1999, fl. fem., L. Kollmann et al. 2350 (MBML, RB, UEC); São Lourenço, Estação Biológica da Caixa d'água, 14.IV.1999, fl. fem., L. Kollmann et al.
2475 (MBML, RB, UEC); Linhares, Reserva Florestal da Companhia Vale do Rio Doce, estrada Peroba Amarela, km 1,1, após o segundo morrote, 15.XI. 2006, fr., A. Quinet 1047 (RB).

Distribuição geográfica e ecologia: espécie até o momento endêmica do Espírito Santo, onde ocorre em formações de Floresta Ombrófila no município de Santa Teresa e em áreas de Floresta de Tabuleiro no município de Linhares na Reserva Florestal da Companhia Vale do Rio Doce.

Etimologia: o epíteto específico pluridomatiata é em alusão ao grande número de domácias na face abaxial das folhas.

Fenologia: coletada com flores nos meses de março, abril e maio e frutos nos meses de abril e setembro.

Status de conservação: espécie categorizada como Em Perigo (EN B2ab(iv)), de acordo com os critérios da IUCN (2001).

No mais recente tratamento do gênero Rohwer (1986) divide Ocotea em dois subgêneros, estes sendo posteriormente organizados em grupos informais de espécie. De acordo com sua classificação infragenérica $O$. pluridomatiata pertence ao subgênero Ocotea Rohwer, que constitui o maior número de espécies do gênero, reunindo tanto as espécies dióicas como monóicas, com estames das series I e II não foliáceos nem liguliformes e cúpula do fruto de margem dupla ou simples.

A nova espécie assemelha-se a Ocotea laxa (Nees) Mez pela morfologia da lâmina foliar, das anteras e pela ausência do pistilóide nas flores masculinas. Difere desta por apresentar lâmina foliar com grande número de domácias nas axilas das nervuras secundárias e terciárias, estames das séries I e II quase tão longos quanto às anteras e frutos com tépalas decíduas, enquanto $O$. laxa apresenta domácias apenas nas axilas das nervuras secundárias, filetes ca. de $1 / 4$ a $1 /$ 5 do compr. das anteras e frutos com tépalas persistentes.

\section{Agradecimentos}

Ao curador do herbário Mello Leitão (MBML) pelo envio de duplicatas; ao Dr. 


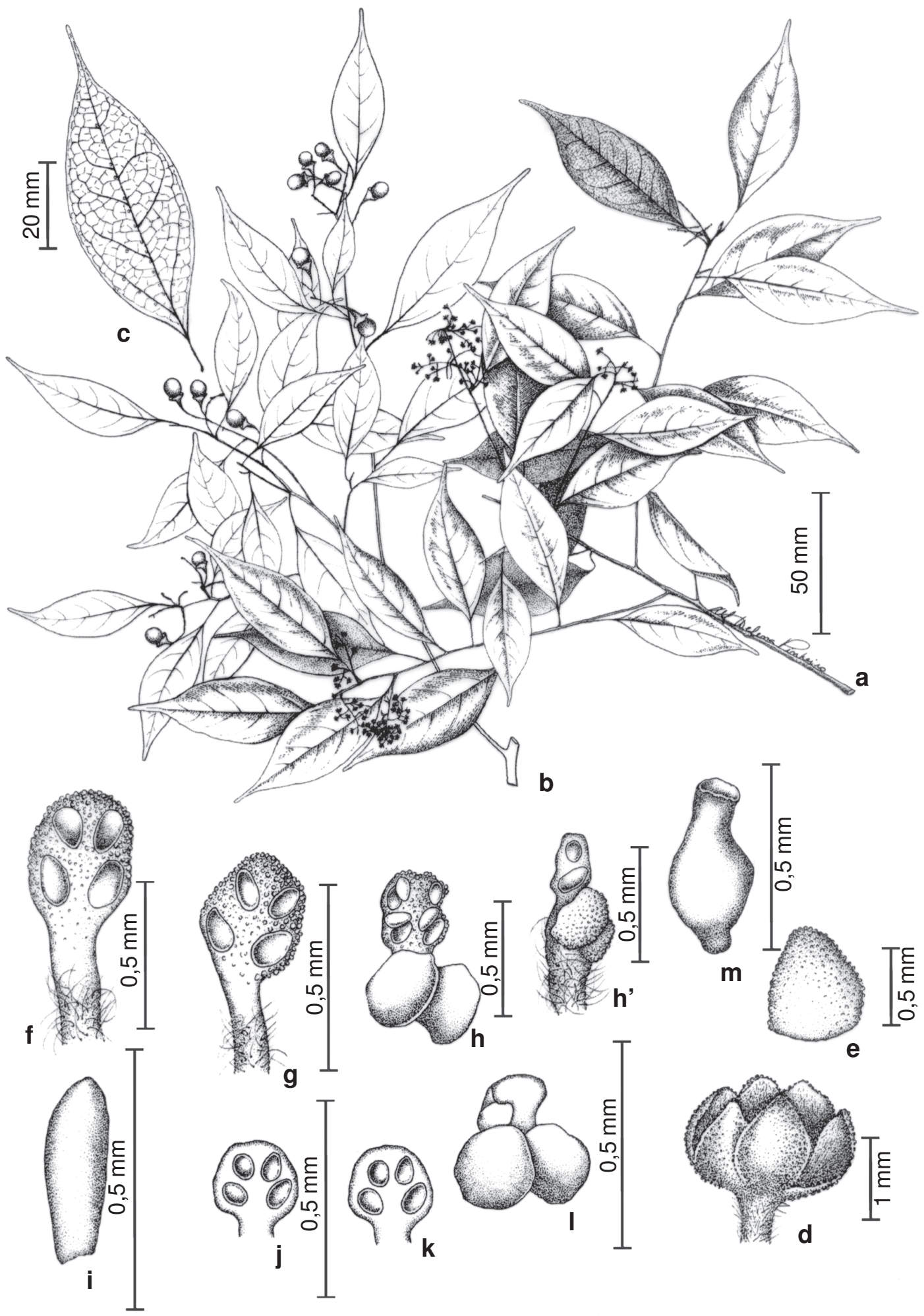

Figura 1 - Ocotea pluridomatiata A.Quinet - a. ramo florífero; b. ramo frutífero; c. folha; d. flor; e. tépala; f. estame da série I; g. estame da série II; h. estame da série III; h'. estame da série III, vista lateral; i. estaminódio da série IV; j. estaminódio da série I; k. estaminódio da série II; 1. estaminódio da série III; m. ovário. (a, c, d-i Lopes 621; b Demuner 11; j-o Kollmann 2350) 
Tarciso Filgueiras pelo auxílio na diagnose em latim; e a Dra. Regina Helena Potsch Andreata pela leitura do manuscrito.

\section{REFERÊNCIAS BIBLIOGRÁFICAS}

IUCN. 2001. IUCN red list categories, v. 3.1. Gland and Cambridge: IUCN Species Survival Commission.

Rohwer, J. G. 1993. Lauraceae. In: Kubitzki, K.; Rohwer, J. G. \& Bittrich, V. (eds.). The families and genera of vascular plants. Vol. 2. Springer-Verlag, Berlin. Pp. 366-391.
Rohwer, J. G. 1986. Prodromus einer Monographie der Gattung Ocotea Aubl. (Lauraceae), sensu lato. Mitteilungen aus dem Institut fur Allgemeine Botanik Hamburg 20: 3-278.

Quinet, A. 2002. Lauraceae. In: Barroso, G. M.; Guimarães, E. F.; Ichaso, C. L. F.; Costa, C. G. \& Peixoto, A. L. (org.). Sistemática de Angiospermas do Brasil. Vol. 1. $2^{\mathrm{a}}$ ed. rev. Ed. Universidade Federal de Viçosa, Viçosa. Pp. 59-64. 